\title{
SeptiFast for diagnosis of sepsis in severely ill patients from a Brazilian hospital
}

\author{
Uso do SeptiFast para diagnóstico de sepse em doentes graves de um hospital brasileiro
}

\author{
Roberta Sitnik ${ }^{1}$, Alexandre Rodrigues Marra ${ }^{1}$, Roberta Cardoso Petroni ${ }^{1}$, Ozires Pereira Santos Ramos ${ }^{1}$, \\ Marinês Dalla Valle Martino ${ }^{1}$, Jacyr Pasternak ${ }^{1}$, Oscar Fernando Pavão dos Santos ${ }^{1}$, \\ Cristóvão Luis Pitangueira Mangueira ${ }^{1}$, João Renato Rebello Pinho ${ }^{1}$
}

\begin{abstract}
Objective: To test and validate a multiplex real-time polymerase chain reaction method for bloodstream infections, as well as to compare the results with conventional blood culture. Methods: A total of 114 consecutive patients with clinical evidence of sepsis were submitted to blood culture and LightCycler ${ }^{\mathrm{TM}}$ SeptiFast tests. Results: More positive specimens $(23 ; 20.2 \%)$ were detected using the LightCycler ${ }^{\mathrm{TM}}$ SeptiFast than the blood culture $(17 ; 14.9 \%)$, with an agreement of $86.8 \%$. Discordant results were seen in four patients positive only to blood culture, ten positive only to LightCycler ${ }^{\mathrm{Tm}}$ Septifast and one to different pathogens found by each test. Infections with microorganisms detected only using blood culture reassured the need to perform both tests. The mean time to results for blood culture was 5 days for negative and 3.5 days for positive results. LightCycler ${ }^{\mathrm{TM}}$ SeptiFast results were achieved in less than 8 hours. Conclusion: LightCycler ${ }^{\mathrm{TM}}$ SeptiFast showed a high potential as a test to be carried out concomitantly with blood culture for sepsis diagnosis in severely ill patients. This test allowed a faster diagnosis of bacterial and fungal infections that helped to reduce hospital stay and to control the use of antibiotics. LightCycler ${ }^{\mathrm{TM}}$ SeptiFast can also eventually detect microorganism and infections that are hardly detected by blood culture, especially Candida non-albicans infections.
\end{abstract}

Keywords: Sepsis/diagnosis; Multiplex polymerase chain reaction; Real-time polymerase chain reaction

\section{RESUMO}

Objetivo: Testar e validar um método molecular multiplex para detecção de infecções sanguíneas, além de comparar os resultados com os obtidos pela hemocultura convencional. Métodos: Os testes de hemocultura e o LightCycler ${ }^{\circledR}$ SeptiFast foram realizados em 114 pacientes consecutivos com evidência clínica de sepse.
Resultados: Mais amostras positivas $(23 ; 20,2 \%)$ foram detectadas pelo LightCycler ${ }^{\circledR}$ SeptiFast do que pela hemocultura $(17 ; 14,9 \%)$, mostrando concordância de $86,8 \%$. Os resultados discordantes foram de quatro pacientes positivos apenas para hemocultura, dez positivos apenas para LightCycler ${ }^{\circledR}$ SeptiFast e um com patógenos diferentes encontrados em cada método. Infecções por micro-organismos não reconhecidos pelo LightCycler ${ }^{\circledR}$ SeptiFast e detectados apelas pela hemocultura confirmam a necessidade da realização dos dois métodos. 0 tempo médio para os resultados da hemocultura foi de 5 dias para amostras negativas e de 3,5 dias para as positivas. 0s resultados pelo LightCycler ${ }^{\circledR}$ SeptiFast foram obtidos em menos de 8 horas. Conclusão: 0 LightCycler ${ }^{\circledR}$ SeptiFast mostrou ser um teste de grande potencial para ser realizado simultaneamente à hemocultura para diagnóstico de sepse em doentes graves, permitindo um diagnóstico mais rápido de infecções por bactérias e fungos e, dessa forma, auxiliando a redução do tempo de hospitalização e racionalização do uso de antibióticos. Eventualmente, o LightCycler ${ }^{\circledR}$ SeptiFast pode detectar inclusive infecções por micro-organismos dificilmente detectáveis via hemocultura, especialmente aquelas causadas por Candida não albicans.

Descritores: Sepse/diagnóstico; Reação multiplex em cadeia da polimerase; Reação em cadeia da polimerase em tempo real

\section{INTRODUCTION}

Sepsis is a leading cause of morbidity and mortality worldwide in hospitalized patients. Studies about sepsis incidence and outcome in Brazil are scarce, but it is considered a major public health problem in intensive care units (ICUs) that causes high costs for health systems. $^{(1,2)}$ There is a great variability in the incidence

\footnotetext{
'Hospital Israelita Albert Einstein, São Paulo, SP, Brazil.

Corresponding author: Roberta Sitnik - Hospital Israelita Albert Einstein, Avenida Albert Einstein, 627/701 - Morumbi - Zip code: $05652-900$ - São Paulo, SP, Brazil - Phone: (55 11) 2151-2105 E-mail: roberta.sitnik@einstein.br

Received on: Aug 6, 2013 - Accepted on: Dec 01, 2013

Conflict of interest: none.

DOI: 10.1590/\$1679-45082014A02932
} 
and mortality of severe sepsis, depending on the method or database used. In the United States, in average, severe sepsis is recorded in $2 \%$ of patients admitted to the hospital and annual average increases about $13 \% .^{(3,4)}$

Sepsis is caused by a heterogeneous group of infectious etiologies. ${ }^{(5)}$ The early diagnosis and the provision of appropriate treatment are correlated with clinical outcome. ${ }^{(6-8)}$ The early identification of a pathogen increases the chance of targeting the correct etiologic agent and may avoid misuse of antibiotics. Nevertheless, determining the antimicrobial susceptibility of a bacterial isolate is always required for prescription of adequate antimicrobial therapy. Kumar et al. ${ }^{(9)}$ have reported that each hour of delay in effective therapy is associated with a 7.6\%-decrease in survival. Conventional blood culture (BC) is the gold standard to detect blood pathogens, but the time required to complete the process can range from 1 to 5 days depending on the organism. Recently, several molecular methods for diagnosis of bloodstream infections were developed, and they are also being used as an adjunct to traditional methods for faster and accurate results. ${ }^{(10-12)}$

Among molecular methods, the first one approved in Brazil by national regulatory agencies was the LightCycler ${ }^{\mathrm{TM}}$ SeptiFast v2.0 (LCS) test (Roche Diagnostics, Manheim, Germany). It is an in vitro nucleic acid amplification test to detect and identify directly on blood samples 25 common pathogens DNA (bacteria and fungi). These microorganisms are responsible for roughly $90 \%$ of all bloodstream infections. ${ }^{(7,13)}$ There are some studies evaluating the diagnostic accuracy and clinical usefulness of LCS, which show that the combination of LCS and BC significantly improve the diagnostic yield, particularly in patients under antibiotic treatment. ${ }^{(14-17)}$

\section{OBJECTIVE}

Considering that rapid pathogen detection may not only facilitates the diagnosis but also provides appropriate and timely therapy, and the few data about this kind of test, particularly in Brazil, the present study tested and validated a multiplex polymerase chain reaction method for bloodstream infections and compared the results obtained with conventional blood culture results.

\section{METHODS}

\section{Patients}

A prospective study was performed involving patients from three different wards of Hospital Israelita Albert
Einstein (HIAE), São Paulo, Brazil: ICU; emergency room (ER); and oncology patients (ONCO). Patients from the Hospital Municipal Dr. Moysés Deutsch (MBOI), located at Jardim Ângela, in the South Peripheral area of São Paulo City, also participated. A total of 114 severely ill patients were enrolled in the study.

The study was conducted in the Molecular Pathology and Microbiology Departments from the Clinical Laboratory from December, 2008 to October 2009. All patients met clinical criteria for sepsis syndrome. Sepsis was defined as an infection plus two or more of the following systemic inflammatory response syndrome criteria: temperature $>38^{\circ} \mathrm{C}$ or $<36^{\circ} \mathrm{C}$; heart rate $>90 / \mathrm{min}$; respiratory rate $>20$ breaths $/ \mathrm{min}$ (or carbon dioxide partial pressure $-\mathrm{PaCO}_{2}<32 \mathrm{mmHg}$ ); white blood cell count $>12,000$ cells $/ \mu \mathrm{L}$ or $<4,000$ cells $/ \mu \mathrm{L}$ (or $>10 \%$ band forms). ${ }^{(18)}$

This study was approved by the Institutional Ethical Committee of HIAE (process number 161/2011). No Informed Consent was used because sample collection was part of patients' standard care.

\section{Multiplex polymerase chain reaction procedure}

Polymerase chain reaction (PCR) tests were performed by the Molecular Pathology Department of the Clinical Laboratory at HIAE. Tests were carried out using the LCS and analyzed by the SeptiFast Identification Software (SIS, Roche Diagnostics) by trained staff on molecular methods. This assay amplifies the internal transcribed spacer (ITS) region between the $16 \mathrm{~S}$ and $23 \mathrm{~S}$ ribosomal DNA sequences of Gram-positive and Gramnegative bacteria, and the $18 \mathrm{~S}$ and $5.8 \mathrm{~S}$ ribosomal DNA sequence of fungi. ITS region is more specific species than ribosomal RNAs and therefore is best suited for species differentiation by melting curve analysis after amplification using dedicated identification software. Although this is not a quantitative method, concentration is related to the PCR cycle in which the sample became detectable (crossing point $-\mathrm{Cp}$ ). Low concentrations of coagulase negative Staphylococci (CoNS) and Streptococci, which reflect the range of workflow contaminations, are not displayed as a positive result.

A single $5 \mathrm{~mL}$ blood sample was collected from each patient in a sterile EDTA tube along with the first set of BCs. Blood samples were stored at $-20^{\circ} \mathrm{C}$ in the laboratory and multiplex PCR testing were done twice a week, according to manufacturer's instructions. MGrade reagents and plastic ware from Roche Diagnostics were used in all procedure steps to avoid bacterial or fungal contamination. 
Strict procedures should be followed to avoid contaminations among samples and from the environmental strains. The lamina flow cabinet used for sample manipulation was extensively wiped with DNA away reagent (Life Technologies, Carlsbad, CA, USA), 70\% ethanol and exposed to ultraviolet germicidal lamp for at least 30 minutes just before its use. Precautions also included unidirectional workflow in the laboratory beginning in the pre-amplification area and moving to the post-amplification area. In addition, for sample manipulations, we used longer powder-free gloves; another pair of regular gloves covering sleeves of the lab coat in order to avoid exposure of skin; and dedicated pipettes.

The mechanical lysis of the specimens $(3 \mathrm{~mL}$ of blood) was performed using the SeptiFast Lys Kit and the MagNA Lyser Instrument. After the lysis, specimens were manually extracted with the SeptiFast Prep Kit. Lysed specimens were incubated at high temperature with a protease and chaotropic lysis buffer that releases nucleic acids and protects the released DNA from DNAses in the blood. After one binding and two washes steps, adsorbed nucleic acids were eluted at high temperature. Amplification was conducted on a LightCycler $^{\mathrm{TM}}$ Instrument (Roche Molecular Systems) with PCR reagents from LCS. Each run also contained a reagent control, a negative control and an internal control introduced into each specimen along with the lysis reagent. Melting curves were obtained and the SeptiFast identification software v1.0 was used to determine the corresponding melting temperature. The total time for sample extraction and DNA amplification to the final result was roughly 6 to 7 hours.

\section{Blood culture}

Conventional $\mathrm{BC}$ was performed in parallel by the Microbiology Department of the laboratory using BACTEC Plus Aerobic/F and BACTEC Plus Anaerobic/F bottles. All bottles were monitored by BACTEC 9240 blood culture system (Becton Dickinson and Company, Flanklin Lakes, New Jersey, USA). When a positive signal was obtained, $\mathrm{BC}$ bottles were removed from the instrument, Gram staining of the BC medium in the bottles was performed and the results rapidly reported to physicians. Samples were platted onto blood agar, chromogenic agar (chromID ${ }^{\mathrm{TM}}$ CPS $^{\mathrm{TM}}$ bioMérieux) and anaerobic blood agar. Identification of bacterial or fungal species as well as antibiotic sensitivity tests were then carried out using the Vitek II system (bioMérieux, Marcy l'Etoile, France) and API 32 C (bioMérieux, Marcy l'Etoile, France) for yeast.

\section{RESULTS}

Sample included 40 (35.1\%) women and 74 (64.9\%) men with mean age of $49.7( \pm 24.8)$ years. Most of the samples were from the ICU (56 samples; $49.1 \%$ ), but we also received samples from ONCO (38 samples; 33.3\%), ER (16 samples; $14.0 \%$ ) and MBOI (4 samples; 3.5\%).

Among the 114 cases, LCS and BC showed positive results in $23(20.2 \%)$ and $17(14.9 \%)$ samples, respectively. A total of 27 cases $(23.7 \%)$ were positive by one of the two assays (either LCS or BC); some of them showing infections by more than one pathogen (total of 32 detected pathogens). Polymicrobial infections were detected in three patients by the LCS and in another by BC. In one patient, two different pathogens were identified by each method. LCS detected Klebsiella pneumoniae/oxytoca while BC detected Burkholderia cepacia. This patient had a positive culture result for $K$. pneumoniae in tracheal aspirate. Considering all positive results as true positives, specificity and positive predictive value (PPV) were $100 \%$ for both LCS and BC. Sensitivity was $81.3 \%$ and negative predictive value (NPV) was $93.5 \%$ for LCS while for BC values obtained were $53.6 \%$ and $86.1 \%$, respectively. The LCS and BC results for these patients with at least one pathogen detected are shown in table 1.

Table 1. Results of LyghtCycler ${ }^{\top m}$ System and blood culture in patients with positive results with at least one detection system

\begin{tabular}{lcc}
\hline Patient & LCS & BC \\
\hline Positive for both systems (concordant) & & Klebsiella pneumoniae \\
2 & Klebsiella pneumoniae/oxytoca & Klebsiella pneumoniae; Pseudomonas aeruginosa \\
8 & Pseudomonas aeruginosa & Pseudomonas aeruginosa \\
9 & Pseudomonas aeruginosa & Klebsiella pneumoniae \\
10 & Klebsiella pneumoniae/oxytoca & Escherichia coli \\
12 & Escherichia coli & Escherichia coli \\
13 & Escherichia coli & Escherichia coli \\
\hline
\end{tabular}


Continuation

Table 1. Results of LyghtCycler ${ }^{\mathrm{TM}}$ System and blood culture in patients with positive results with at least one detection system

\begin{tabular}{|c|c|c|}
\hline Patient & LCS & BC \\
\hline 17 & Pseudomonas aeruginosa & Pseudomonas aeruginosa \\
\hline 18 & Staphylococcus aureus; Pseudomonas aeruginosa & Pseudomonas aeruginosa \\
\hline 25 & Escherichia coli & Escherichia coli \\
\hline 26 & Streptococcus pneumoniae; Klebsiella pneumoniae/oxytoca & Streptococcus pneumoniae \\
\hline 27 & Candida albicans & Candida albicans \\
\hline \multicolumn{3}{|c|}{ Positive for both systems (discordant) } \\
\hline 11 & Klebsiella pneumoniae/oxytoca & Burkholderia cepacia \\
\hline \multicolumn{3}{|c|}{ Positive only with LCS } \\
\hline 1 & Pseudomonas aeruginosa & Negative \\
\hline 3 & Pseudomonas aeruginosa & Negative \\
\hline 4 & Candida tropicalis & Negative \\
\hline 6 & Staphylococcus aureus & Negative \\
\hline 7 & Pseudomonas aeruginosa & Negative \\
\hline 19 & Staphylococcus aureus; Candida albicans; Candida glabrata & Negative \\
\hline 20 & Klebsiella pneumoniae/oxytoca & Negative \\
\hline 21 & Enterobacter cloacae/aerogenes & Negative \\
\hline 22 & Pseudomonas aeruginosa & Negative \\
\hline 24 & Pseudomonas aeruginosa & Negative \\
\hline \multicolumn{3}{|c|}{ Positive only with $\mathrm{BC}$} \\
\hline 5 & Negative & Staphylococcus epidermidis \\
\hline 15 & Negative & Burkholderia cepacia \\
\hline 16 & Negative & Burkholderia cepacia \\
\hline
\end{tabular}

LCS: LyghtCycler System; BC: blood culture.

Table 2. Pathogens detected by LightCycler ${ }^{\mathrm{TM}}$ SeptiFast and blood culture

\begin{tabular}{|c|c|c|c|}
\hline & Only PCR & Only HC & PCR and HC \\
\hline \multicolumn{4}{|l|}{ Gram-negative bacteria } \\
\hline Pseudomonas aeruginosa & 5 & 0 & 4 \\
\hline Klebsiella pneumoniae/oxytoca & 3 & $1^{*}$ & 2 \\
\hline Escherichia coli & 0 & 0 & 4 \\
\hline Enterobacter cloacae/aerogenes & 1 & 0 & 0 \\
\hline \multicolumn{4}{|l|}{ Gram-positive bacteria } \\
\hline Staphylococcus epidermidis (CoNS) & $0^{* *}$ & 2 & 0 \\
\hline Staphylococcus aureus & 3 & 0 & 0 \\
\hline Streptococcus pneumoniae & 0 & 0 & 1 \\
\hline \multicolumn{4}{|l|}{ Fungi } \\
\hline Candida albicans & 1 & 0 & 1 \\
\hline Candida tropicalis & 1 & 0 & 0 \\
\hline Candida glabrata & 1 & 0 & 0 \\
\hline \multicolumn{4}{|l|}{$\begin{array}{l}\text { Gram-negative bacteria not detected by } \\
\text { SeptiFast }\end{array}$} \\
\hline Burkholderia cepacia & ND & 3 & 0 \\
\hline
\end{tabular}

* Klebsiella pneumonia; ** considered as a contaminant by SeptiFast if Cp is higher than 20.

PCR: polymerase chain reaction; CoNS: coagulase negative Staphylococc; ND: not detected; BC: blood culture.

Overall concordance among $\mathrm{BC}$ and LCS was $86.8 \%$. Time for BC negative results was 5 days and 3.5 days for positive results. LCS results could be achieved in less than 8 hours.
The isolated BC positive result for Staphylococcus epidermidis reflects a software feature that excludes CoNS positive results with $\mathrm{Cp}$ values higher than 20 (concentration lower than $100 \mathrm{CFU} / \mathrm{mL}$ ). This reduces the positive rate based on the assumption that they are contaminants and not real causative agents for infection.

For fungi, only one sample was positive for Candida albicans using BC, but other three patients were positive for C. albicans, Candida tropicalis and Candida glabrata using the LCS.

The higher rate of positive results was obtained from ICU patients $28.6 \%$. ER and ONCO patients had a positivity rate of $18.8 \%$ and $10.5 \%$, respectively.

Detected pathogens are listed in table 2. Gramnegative infections were more frequent and the most common one was the Pseudomonas aeruginosa, detected in $7.9 \%$ of tested patients.

\section{DISCUSSION}

Results obtained in this study show that LCS is a useful system for rapid diagnosis of sepsis in severely ill patients. The agreement between BC and LCS in our study was $86.8 \%$. Concordant results in previous studies 
with different kinds of patient populations ranged from 70 to $88 \%$. $^{(19,20)}$

All Gram-negative rods detected by LCS could be real pathogens. Although non-fermentative bacilli, such as $P$. aeruginosa, Acinetobacter baumannii and Stenotrophomonas maltophilia can be found as environmental contaminants, they are recognized as an important cause of nosocomial infection mainly in immunosuppressed individuals.

CoNS are frequently isolated from blood cultures, in which they may be only a contaminant or the cause of bacteraemia. Despite the careful manipulation of reagents during reaction set up and during extraction up to the real time amplification, considering that human skin and upper respiratory tract are populated with some microorganisms identified by SeptiFast, one could expect a high possibility of CoNS contamination. Indeed, CoNS were detected by BC in two cases. In one of them, CoNS was also detected by LCS with high Cp but was excluded by the LCS software interpretation. This result reinforces the importance of the precautions taken to avoid contamination during all the process, i.e., from sample collection to PCR amplification. Other authors had shown that LCS has a higher positivity rate and a lower contamination rate than BC. ${ }^{(20,21)}$

Even with BC, determining whether an isolate of CoNS represents a true bacteremia is difficult. García et al. ${ }^{(22)}$ analyzed patients with one or more positive blood culture for CoNS and found a statistically significant difference in the median time to positivity between the clinical bacteremia and contaminations (19.4 versus 22.7 hours; $p=0.02$ ), showing that time to positivity may be a useful parameter for the diagnosis of true CoNS bacteremia. In the present work, in two patients with positive results for $S$. epidermidis detected only by $\mathrm{BC}$, incubation times to positivity were 22 and 25 hours, which can suggest a possible contamination, especially in the last isolation.

Regarding fungal detection, the conventional blood culture identified only $C$. albicans in one sample. Blood culture system may fail in identifying Candida nonalbicans, as showed by Fernandez et al. ${ }^{(23)}$ These authors also showed that the mean time to positive yeast detection for $C$. albicans was $35.3 \pm 18.1$ hours, whereas for $C$. glabrata it was $80.0 \pm 22.4$ hours $(\mathrm{p}<0.0001)$. LCS was positive for three Candida species: $C$. albicans, $C$. tropicalis and $C$. glabrata. As expected, only the first species was also detected by $\mathrm{BC}$ in one of the two positive samples for fungal infections identified by LCS. Fungal pathogen detection was substantially improved with the use of LCS.
Some relevant pathogens were not detected by LCS but only by BC. In our study, B. cepacia was detected in 3 patients only by $\mathrm{BC}$.

Discordant results may have different causes. The use of antibiotic before blood sample collection can interfere with culture leading to non-viable microorganism with a LCS positive result. Blood cultures are reported to be negative in about $50 \%$ of clinically sepsis cases. ${ }^{(8)}$ On the other hand, a larger volume of blood collected for $\mathrm{BC}$ tests or an infection by an organism not included on SeptiFast master list could explain positive BC and negative LCS results. ${ }^{(24)}$

Analyzing the different clinical wards studied, the higher positive rate was observed on the ICU (28.6\%), showing clinical utility of the molecular test for this kind of patients. However, in the other wards tested, positive samples were also identified pointing to the impact of implementing the LCS for every patient with suspected sepsis, independently from the clinical ward, provided that they met some pre-established clinical criteria. This is an important point to discuss because clinicians will be able to use a more appropriate antimicrobial therapy for their patients, and as we know this clinical practice is important for decreasing mortality in septic patients. ${ }^{(25,26)}$

Time for result processing is the strongest advantage for using real time PCR. In the present study, because of the need to maintain a separated area of the laboratory and a team dedicated to this reaction, LCS could not be performed at least once a day, that would be needed to keep the turnaround time (TAT) little enough to better evaluate its effects on patient management.

The results obtained were not considered by physicians, since our main aim was to test the feasibility of the LCS in our laboratory and verify its performance characteristics. Ideally, using a team devoted to LCS execution, TAT can be reduced to less than 4 hours, using an automated extraction ${ }^{(27)}$ and its results significantly improved treatment and outcome of patients, even using samples other than blood. ${ }^{(11,14,16,28)}$

The major limitation of LCS is the need of a specialized laboratory that follows strictly guidelines to avoid contaminations from microorganisms, which might be present in the environment, manipulators' skin and secretions. This need is greater than those needs for other nucleic acid amplifications tests that driven to other agents not presented in the environment. Because of LCS high complexity degree, its limitations restrain the use in most clinical routine laboratories. On the other hand, it seems an interesting assay to speed up the identification of microorganisms infections in severely compromised patients. We could show the feasibility of the molecular test in our laboratory that was subject 
to the compliance with rules to avoid contamination described before LCS validation, which was approved after a detailed study of laboratory workflow in order to avoid environmental contamination and sample-tosample carryover, as described on the this study method section.

\section{CONCLUSION}

To our knowledge, this is the first study in Brazil using the LightCycler ${ }^{\mathrm{TM}}$ SeptiFast methodology. We detected more positive specimens in LightCycler ${ }^{\mathrm{TM}}$ SeptiFast than using the blood culture with an overall agreement of $86.8 \%$. Infections by microorganisms that are not identified by SeptiFast were detected only by blood culture, reassuring the need to perform both tests in the routine. Also, LightCycler ${ }^{\mathrm{TM}}$ SeptiFast could not detect resistance profile, except the Staphylococcus aureus to oxacilin. LightCycler ${ }^{\mathrm{TM}}$ SeptiFast showed a high potential as an important test to be carried out concomitantly with blood culture to diagnose patients with suspicion of sepsis. It also allowed a faster diagnosis of bacterial and fungal infections so that reducing hospitalization and antibiotics use. LightCycler ${ }^{\mathrm{TM}}$ SeptiFast can also eventually detect some microorganisms infections that are hardly found by blood culture, especially Candida non-albicans infections.

\section{ACKNOWLEDGEMENTS}

We thank patients and physicians who participated in the initial trial of the SeptiFast System at our hospital; the Molecular Pathology and Microbiology Pathology Departments of the Clinical Laboratory for the excellent technical work; and Eduardo Machado for English language review. We also thank Roche Diagnostics that donated all material needed for multiplex polymerase chain reaction testing and provided training on test workflow to the team of our laboratory.

\section{REFERENCES}

1. Silva E, Pedro M de A, Sogayar AC, Mohovic T, Silva CL, Janiszewski M, Cal RG, de Sousa EF, Abe TP, de Andrade J, de Matos JD, Rezende E, Assunção M, Avezum A, Rocha PC, de Matos GF, Bento AM, Corrêa AD, Vieira PC, Knobel E; Brazilian Sepsis Epidemiological Study. Brazilian Sepsis Epidemiological Study (BASES study). Crit Care. 2004;8(4):R251-2.

2. Sogayar AM, Machado FR, Rea-Neto A, Dornas A, Grion CM, Lobo SM, Tura BR, Silva CL, Cal RG, Beer I, Michels V, Safi J, Kayath M, Silva E; Costs Study Group - Latin American Sepsis Institute. A multicentre, prospective study to evaluate costs of septic patients in Brazilian intensive care units. Pharmacoeconomics. 2008;26(5):425-34.

3. Gaieski DF, Edwards M, Kallan MJ, Carr BG. Benchmarking the incidence and mortality of severe sepsis in the United States. Crit Care Med. 2013;41(5):1167-74.
4. Angus DC, van der Poll T. Severe sepsis and septic shock. N Engl J Med. 2013;369(9):840-51.

5. Angus DC, Linde-Zwirble WT, Lidicker J, Clermont G, Carcillo J, Pinsky MR. Epidemiology of severe sepsis in the United States: analysis of incidence, outcome, and associated costs of care. Crit Care Med. 2001;29(7):1303-10.

6. Gao F, Melody T, Daniels DF, Giles S, Fox S. The impact of compliance with 6-hour and 24-hour sepsis bundles on hospital mortality in patients with severe sepsis: a prospective observational study. Crit Care. 2005;9(6):R764-70.

7. Kollef MH, Sherman G, Ward S, Fraser VJ. Inadequate antimicrobial treatment of infections: a risk factor for hospital mortality among critically ill patients. Chest. 1999;115(2):462-74.

8. Dellinger RP, Carlet JM, Masur H, Gerlach H, Calandra T, Cohen J, GeaBanacloche J, Keh D, Marshall JC, Parker MM, Ramsay G, Zimmerman JL, Vincent JL, Levy MM; Surviving Sepsis Campaign Management Guidelines Committee. Surviving Sepsis Campaign guidelines for management of severe sepsis shock. Crit Care Med. 2004;32(3):858-73. Erratum in: Crit Care Med. 2004;32(6):1448. Crit Care Med. 2004;32(10):2169-70.

9. Kumar A, Roberts D, Wood KE, Light B, Parrillo JE, Sharma S, et al. Duration of hypotension before initiation of effective antimicrobial therapy is the critical determinant of survival in human septic shock. Crit Care Med. 2006;34(6):1589-96.

10. Klouche M, Schröder U. Rapid methods for diagnosis of bloodstream infections. Clin Chem Lab Med. 2008;46(7):888-908.

11. Lehmann LE, Alvarez J, Hunfeld KP, Goglio A, Kost GJ, Louie RF et al. Potential clinical utility of polymerase chain reaction in microbiological testing for sepsis. Crit Care Med. 2009;37(12):3085-90.

12. Ecker DJ, Sampath R, Li H, Massire C, Matthews HE, Toleno D, et al. New technology for rapid molecular diagnosis of bloodstream infections. Expert Rev Mol Diagn. 2010;10(4):399-415.

13. Harbarth S, Garbino J, Pugin J, Romand JA, Lew D, Pittet D. Inappropriate initial antimicrobial therapy and its effect on survival in a clinical trial of immunomodulating therapy for severe sepsis. Am J Med. 2003;115(7):529-35.

14. Lehmann LE, Hunfeld KP, Emrich T, Haberhausen G, Wissing H, Hoeft A, et al. A multiplex real-time PCR assay for rapid detection and differentiation of 25 bacterial and fungal pathogens from whole blood samples. Med Microbiol Immunol. 2008;197(3):313-24.

15. Dark P, Dunn G, Chadwick P, Young D, Bentley A, Carlson G, et al. The clinical diagnostic accuracy of rapid detection of healthcare-associated bloodstream infection in intensive care using multipathogen real-time PCR technology. BMJ Open. 2011;1(1):e000181.

16. Lucignano B, Ranno S, Liesenfeld O, Pizzorno B, Putignani L, Bernaschi $P$, et al. Multiplex PCR allows rapid and accurate diagnosis of bloodstream infections in newborns and children with suspected sepsis. J Clin Microbiol. 2011;49(6):2252-8.

17. Dark P, Wilson C, Blackwood B, McAuley DF, Perkins GD, McMullan R et al. Accuracy of LightCycler ${ }^{\circledR}$ SeptiFast for the detection and identification of pathogens in the blood of patients with suspected sepsis: a systematic review protocol. BMJ Open. 2012;2(1):e000392.

18. Bone RC, Balk RA, Cerra FB, Dellinger RP, Fein AM, Knaus WA, et al. Definitions for sepsis and organ failure and guidelines for the use of innovative therapies in sepsis. The ACCP/SCCM Consensus Conference Committee. American College of Chest Physicians/Society of Critical Care Medicine. Chest. 1992;101(6):1644-55.

19. Maubon D, Hamidfar-Roy R, Courby S, Vesin A, Maurin M, Pavese P, et al. Therapeutic impact and diagnostic performance of multiplex PCR in patients with malignancies and suspected sepsis. J Infect. 2010;61 (4):335-42.

20. Pasqualini L, Mencacci A, Leli C, Montagna P, Cardaccia A, Cenci E et al. Diagnostic performance of a multiple real-time PCR assay in patients with suspected sepsis hospitalized in na internal medicine ward. J Clin Microbiol. 2012;50(4):1285-8

21. Westh H, Lisby G, Breysse F, Böddinghaus B, Chomarat M, Gant V, et al Multiplex real-time PCR and blood culture for identification of bloodstream 
pathogens in patients with suspected sepsis. Clin Microbiol Infect. 2009;15(6):544-51.

22. García P, Benítez R, Lam M, Salinas AM, Wirth H, Espinoza C, et al. Coagulasenegative staphylococci: clinical, microbiological and molecular features to predict true bacteraemia. J Med Microbiol. 2004;53(Pt 1):67-72.

23. Fernandez J, Erstad BL, Petty W, Nix DE. Time to positive culture and identification for Candida blood stream infections. Diagn Microbiol Infect Dis. 2009;64(4):402-7.

24. Paolucci M, Landini MP, Sambri V. Conventional and molecular techniques for the early diagnosis of bacteraemia. Int J Antimicrob Agents. 2010;36 Suppl 2:S6-16.

25. Ibrahim EH, Sherman G, Ward S, Fraser VJ, Kollef MH. The influence of inadequate antimicrobial treatment of bloodstream infections on patient outcomes in the ICU setting. Chest. 2000;118(1):146-55

26. Zaragoza R, Artero A, Camarena JJ, Sancho S, González R, Nogueira JM. The influence of inadequate empirical antimicrobial treatment on patients with bloodstream infections in an intensive care unit. Clin Microbiol Infect. 2003;9(5):412-8.

27. Regueiro BJ, Varela-Ledo E, Martinez-Lamas L, Rodriguez-Calviño J, Aguilera A, Santos A, et al. Automated extraction improves multiplex molecular detection of infection in septic patients. PloS One. 2010;5(10):e13387.

28. Lehmann LE, Herpichboehm B, Kost GJ, Kollef MH, Stüber F. Cost and mortality prediction using polymerase chain reaction pathogen detection in sepsis: evidence from three observational trials. Crit Care. 2010;14(5):R186. 